\title{
LA VISIÓN DE LA JUSTICIA Y LOS DERECHOS DEL JUSTICIABLE EN LA CONSTITUCIÓN DE I8I2*
}

\author{
Óscar AlZAGA VilLAAMIL \\ CATEDRÁTICO DE DERECHO CONSTITUCIONAL. \\ De la ReAl ACAdemia de CienCias Morales y Políticas
}

Como introito recordemos que Toymbee sugirió sagazmente que el historiador confesase en su prólogo sus prejuicios para que el lector los conociese. Empezaré así por reconocer, en parcos brochazos, mis pautas valorativas sobre la obra constituyente doceañista.

Primer punto de partida: la Nación española es un concepto muy anterior a I8ı。. Es un término en uso desde el Renacimiento. Pero en Cádiz por vez primera la Nación es titular de la soberanía aunque en el marco de la lectura escolástica que de ella hizo Muñoz Torrero. Y esta es la clave de la bóveda de la «revolución española». Me remito al librito de Flórez Estrada: «Introducción para la Historia de la Revolución de España», Londres, I8ıo. Cierto es que los conceptos de Soberanía nacional y Constitución política, -como sostuvieron José Antonio Maravall y Antonio Elorza- eran manejados por algunos de nuestros ilustrados aun antes de la revolución francesa. Pero solo en Cádiz se construye su lectura moderna a la española. Argüelles al rebatir el origen de la soberanía rechaza las tesis contractualistas roussonianas, por «metafísicas» (sic) percibiéndose que conocía bien el «Tratado de los Sofismas políticos» de Jeremy Bentham -escrito en Londres, I807- y en sus palabras y en la de otros diputados se observa su formación escolástica: conciben la nación como un «cuerpo místico» y conocen las aportaciones de Vitoria, Mariana, De Soto, Covarrubias, Vázquez de Menchaca y sobre todo la tesis de Suárez expuesta en estas palabras: «La potestad civil cuando se halla en un hombre o príncipe por derecho legítimo y ordinario, procede de la comunidad próxima o remotamente y no puede ser de otro modo para que tal potestad sea justa».

Segunda premisa: La comprensión del enfoque historicista, en nuestra opinión, permite entender la singularidad de aquel proceso constituyente. Se afirma que el pueblo español tiene una tradición de vida pública y disfrute de libertades superior al francés. Eso era muy cierto en la aprobación por las Cortes de los tributos y en el control del gasto así como en muchas otras facetas del Derecho público dotadas de algunas raíces medievales, pero no en todas. En los debates de Cádiz se aspira a una legitimidad enraizada en nuestro siglo XI, en las Juntas y Concilios celebrados en tiempos de los Visigodos y en una serie de

\footnotetext{
* Conferencia pronunciada el 29 de noviembre de 20I2, en la Universidad de La Rioja, en el marco de las Jornadas «200 años de Constitucionalismo español», organizadas al amparo del convenio Parlamento de La Rioja-UR y dentro del Seminario Permanente del Departamento de Derecho.
} 
grandes hitos medievales, entre los que destaca el «Liber Iudiciorum». La revolución española se apoya en su lectura de la historia de nuestras Cortes y de las libertades de nuestro pueblo, como creen que en el siglo XVII habían hecho los ingleses.

Para una parte de los constituyentes de Cádiz Inglaterra es mejor tierra de libertades que la Francia invasora. Pensaban que la Constitución inglesa era la historia misma de Inglaterra puesta en acción, y que el sistema constitucional de Montesquieu o el de Benjamín Constant no eran sino reinterpretaciones de la Constitución inglesa. Aquellos diputados eran historicistas, unos por convicción -como razonaron bien Sánchez Agesta y Pérez-Prendes- y otros por pragmatismo -como apuntaron Tierno Galván y Fernández Almagro-, que buscaban facilitar la aceptación de la Constitución por las gentes de cultura tradicional. Para el liberalismo doceañista era necesaria una Constitución escrita para lograr la limitación jurídica del poder al servicio del bien común y de los derechos históricamente percibidos como necesarios -no estrictamente disfrutados en la historia-. En términos ciceronianos, creían que la Historia era la gran maestra de la vida no sólo en cuanto a soluciones, sino también en cuanto a errores a subsanar.

En consecuencia, la Constitución de Cádiz será así en lo que respecta a su tratamiento de la Administración de justicia, fruto de la combinación de dosis de escolasticismo, mimetismo hacia las llamadas «convenciones constitucionales» inglesas y hacia fórmulas norteamericanas y francesas -vistas frecuentemente como versiones escritas de la Constitución histórica inglesa-, así como aportaciones de un historicismo inspirador del restablecimiento o del establecimiento de instituciones políticas modernas. Y será también fruto del pensamiento español de la ilustración y de la reflexión empírica.

Expondremos como los constituyentes reunidos en la Isla de León -en un cuarenta por ciento juristas eclesiásticos o laicos- se plantean la organización y funcionamiento de la Justicia. Partieron de una idea fuerza: la necesidad de garantizar la independencia de los jueces. La falta de independencia era el mayor vicio a subsanar en la justicia heredada.

En el reinado de Carlos III se habían desplegado esfuerzos ilustrados por reordenar la justicia. Fue el caso del Conde de Aranda, de Campomanes, de Foronda, del Duque de Almodóvar, o de Menéndez Valdés. Pero con escaso éxito. Y el Rey no dejó de nombrar y cesar jueces. Seguía vigente el espíritu del Fuero Viejo de Castilla, en que el nombramiento de los «Justicias» era uno de los cuatro atributos del Rey -junto a «moneda, fonsadera e suos yantares»-.

A fines del siglo XVIII, pese a que durante casi cuatro años fue ministro de justicia de Carlos IV el ilustrado Jovellanos, -que en I8or fue cesado y encarcelado-, no se había respetado la independencia judicial. Además el número de jurisdicciones especiales y privilegiadas era casi infinito. En I766, por ejemplo, en la villa de Madrid había sesenta y cinco jurisdicciones especiales. En toda España el mapa jurisdiccional era caótico. Y el nivel de los jueces bajísimo.

En los albores del siglo XIX se sabía que Inglaterra tenía una tradición bien distinta, cuyo hito más paradigmático había sido el enfrentamiento del Justicia Mayor, Sir Edward Coke con Jacobo I al que le recordó que la interpretación de la Ley no podía basarse solo en la razón natural sino en la técnica jurídica que dominaban los jueces, pero no el Rey, subrayando que como decía Bracton: «Quod rex non debe ese sub himen, sed sub Deo et lex». Pero era más cierto que en la Inglaterra del siglo XVII, la opinión de Coke había colisionado con la doctrina absolutista inglesa sintetizada en ${ }^{6} 637$ por el juez Berkeley en estas palabras: «La Ley es en sí un viejo y fiel servidor del Rey, es un instrumento o medio que utilizada para gobernar a su pueblo. Nunca oí ni leí que lex fuera Rex pero es común y más verdad que Rex es Lex, porqué es Lex loquens». En I64I el Parlamento inglés abolió los tribunales extraordinarios. La revolución inglesa de i688 proclamó la independencia de los 
jueces, pero estos pasaron a estar encabezados por el Parlamento en términos que en ocasiones mediatizaban su independencia.

Y aunque Montesquieu afirmó que «(no) hay libertad si el poder judicial no está separado del legislativo ni del ejecutivo», pues, como lector -entre otros- de Locke y Harrington, le horrorizaba que el juez tuviese la fuerza de un opresor, lo cierto es que sus ideas tuvieron solo influjo parcial en la Revolución Francesa. Los círculos jacobinos avanzaron hacia la concentración del poder en un sector de la Asamblea, que asumió funciones de acusación criminal bajo la batuta, entre otros, de Robespierre. La propia Constitución francesa de I79I en sus artículos 9 y io había mantenido los decretos acusatorios de la Asamblea Nacional Legislativa, precedente que fue expresamente rechazado por nuestros primeros constituyentes. Igualmente esta Constitución francesa preveía en sus artículos 25 y 27 la figura de los comisarios del Rey ante los tribunales, que podían perseguir los presuntos excesos de los jueces ante el Tribunal de Casación y -previa denuncia de la Asamblea Legislativa- ante la Alta Corte Nacional. Ni esos comisarios regios ni esa Alta Corte están recogidos en nuestra Constitución española de I8I2, celosa guardiana de la independencia de los jueces.

El modelo español fue distante del francés al optar por la independencia judicial pura, sometiendo al juez solo al principio de legalidad. Es verdad que las aportaciones de Blackstone y la obra del ginebrino De Lolme, titulada «Constitución de Inglaterra o el Sistema de gobierno inglés» (I77I) editada en Oviedo, en I8I2, difundieron entre nuestros liberales la tesis de que el juez está vinculado a la Ley. Pero el imperio de la ley era para aquellos diputados también hijo, de una parte, de la tradición visigótica, conforme a la que los códigos bárbaros habían de ser respetados por el Rey y, de otra, de las doctrinas tomistas sobre la ley humana, que deriva de la natural y se concreta por la razón. De manera que el racionalismo doceañista es de inspiración tomista e inglesa al tiempo.

Un primer paso lo dio Agustín de Argüelles, antes de que las Cortes iniciaran su labor constituyente, al presentar en la sesión de 29 de enero de I8II la proposición -que las Cortes aprobaron- de que se nombrara una Comisión para redactar un Reglamento provisional del Poder judiciario, que no pasó de la condición de proyecto. Análogo impulso aportó Argüelles al promover la abolición de la tortura (o tormento) y de los eufemísticamente denominados «apremios».

Ya el ig de abril de i8II un grupo de «liberales» -terminología creada y exportada desde Cádiz, como sabemos- había presentado un Proyecto de Reglamento para la abreviación de las causas criminales, que era reflejo, de las numerosas cartas quejosas remitidas por presos o por sus familiares a las Cortes, y de la experiencia acumulada por la Comisión de Justicia tras visitar toda suerte de juzgados y centros penitenciarios con la finalidad de conocer directamente los abusos que pudieran darse.

El histórico Decreto de las Cortes, de 24 de septiembre de i8ıo, contenía reflejos de la doctrina de la división de poderes. Se ha escrito que esta doctrina era útil a los liberales doceañistas para importar la noción decantada en la Inglaterra del siglo XVIII sobre la Corona como un «poder neutro», patente en los escritos de Hume, Blasckstone o Burke; pero en verdad en nuestra Constitución de Cádiz se reservaron al Rey poderes básicamente análogos a los que la Constitución norteamericana había otorgado a su Presidente. Pero de tal doctrina lo que especialmente a los doceañistas interesaba era asegurar, la independencia de los tribunales, entendida como condición inexcusable para la protección de las libertades civiles de los españoles frente a los posibles abusos del poder político. Esta perspectiva preside el «Discurso preliminar», donde leemos: «Para que la potestad de aplicar las leyes a los casos particulares no pueda convertirse jamás en instrumento de tiranía, se separan de tal modo las funciones de juez de cualquiera otro acto de la autoridad soberana, que nunca podrán ni las Cortes ni el Rey ejercerlas bajo ningún pretexto». 
La Constitución de i8ı2 asienta en su título V -del que son ponentes Argüelles y Espiga- las paredes maestras («De los Tribunales y de la Administración de Justicia en lo civil y en lo criminal») en nada menos que sesenta y siete artículos. De manera que nuestra primera Carta Magna va mucho más allá que la Constitución francesa de I79I, que solo dedicó a esta materia 27 breves preceptos, y que, salvando algunos paralelismos, responde a técnica legislativa más simple. El constitucionalismo francés -incluidos los textos de I793, I795 y I799, eran bien conocidos por nuestros primeros constituyentes- ejerció una influencia innegable pero no grande en la materia que nos ocupa porque no se tomó como modelo respecto de la organización y funcionamiento de la justicia.

El texto de I8I2 es el que dedica más atención a esta materia en la historia del constitucionalismo europeo. La Comisión Constitucional de aquellas Cortes dedicó a este Título V sus esfuerzos desde el 28 de agosto, al 5 de noviembre de i8II en debates secretos de los que las actas no dejan mucho más rastro que los preceptos tratados cada día. Y el Pleno abordó la materia: desde el I5 de noviembre de I8II hasta el 26 de diciembre de I8II de lo que los Diarios de sesiones reflejan unas veces resúmenes y otras textos taquigrafiados, suficientes para tener noción de las argumentaciones y de la dialéctica que se esgrimen en los debates. Las Actas constatan los acuerdos adoptados, pero nunca el resultado numérico de las votaciones. De modo que el estudio de este proceso constituyente tropieza con algunas limitaciones.

El primer gran debate que sobre la justicia registró el pleno fue en torno al art. 243, que rezaba: «Ni las Cortes ni el Rey podrán ejercer en ningún caso las funciones judiciales, avocar causas pendientes, ni mandar abrir los juicios fenecidos». Esta redacción, más precisa que la contenida al respecto por la Constitución francesa de I79I, tropezó con la oposición de los diputados más tradicionales como los Sres. Torrero o Gómez Fernández, quienes ante aquella proclamación de la independencia judicial, procuraron reservar alguna parcela jurisdiccional a la prerrogativa regia y, para facilitarlo, propusieron que se hiciera análoga reserva en favor de las propias Cortes. La mayoría liberal se opuso con tozudez, a través de los Sres. Muñoz Torrero, Villanueva, el Conde de Toreno, Gordillo, Oliveros y Argüelles, que demostraron, por cierto, gran conocimiento de la problemática real que latía bajo un precepto capital, de naturaleza garantista.

Pasamos ahora a centrarnos en la atención superlativa que nuestra primera Constitución dedica a los derechos del justiciable. Hagamos una anotación previa: la Constitución de I8I2 no contenía una parte dogmática. Es decir, no poseía una «Declaración de Derechos del hombre y del ciudadano» como la francesa de i789; el Pleno ni siquiera mantuvo los arts. 6 a io, que la Comisión había dedicado a los derechos fundamentales básicos. Y ¿jporqué la Constitución del I2 no es iusnaturalista en materia tan capital, ni sigue los modelos inglés, francés o norteamericano -cuando este último ya en I79I había aprobado las io primeras enmiendas garantizando derechos y libertades-? En mi opinión, porque no se quería reconocer derechos a todos los hombres, como una derivación de su dignidad personal. Y ello por dos razones: La primera, porque a los invasores franceses se les consideraba enemigos, a los que, se les hacía la guerra, para su destrucción. Los aguafuertes y lienzos de Goya dan testimonio de una crueldad, nada ilustrada, por ambos bandos. La segunda, porque ni siquiera las cortes aprobaron la propuesta de la Comisión sobre la «igualdad ante la ley», excusas a un lado, por la extendida esclavitud, en nuestras colonias. A la esclavitud dedica la Constitución gaditana uno de sus artículos más deliciosos, el 22, que es toda una perla que no me resisto a leer: «A los españoles que por cualquier línea son habidos y reputados por originarios del África, les queda abierta la puerta de la virtud y del merecimiento para ser ciudadanos: en su consecuencia las Cortes concederán carta de ciudadano, a los que hicieren servicios calificados a la Patria, o a los que se distingan por su talento, aplicación y conducta, con la condición de que sean hijos de legítimo matrimonio de padres ingenuos; de que estén casados con mujer ingenua, y avecindados en los dominios de las Españas, y de que ejerzan alguna profesión, oficio o industria útil con un capital propio». Lo obvio que subyace a tan 
entrañable tenor literal no precisa de glosa. No nos desviemos y volvamos al Título V.

En Cádiz se sigue la política constitucional de insertar numerosos preceptos con garantías puntuales para los justiciables, especialmente en la órbita penal. En muchos casos por primera vez en la historia del constitucionalismo universal.

El conjunto de derechos de que estaos hablando es novedoso e impresionantemente completo para el constitucionalismo de la época. Enumeraremos los más relevantes:

$I^{\circ}$. El arrestado ha de ser puesto a disposición del juez dentro de las 24 horas de su detención (art. 290), tras un debate sobre si ello estaba así dispuesto indirectamente en las Leyes de Partidas. Pero no en las 72 horas del art. II de la Constitución francesa de I79I.

$2^{\circ}$. Destilando modernidad el art. 29I doceañista reza: «La declaración del arrestado será sin juramento, que a nadie ha de tomarse en materias criminales sobre hecho propio». Su contenido, desconocido en el constitucionalismo previo francés y en el norteamericano tanto previo como actual, se basó en los usos de algunas de nuestras costumbres históricas que se consideraron más garantistas que los usos de otras regiones, como Cataluña, donde se declaraba bajo juramento. La solución innovadora gaditana está hoy vigente en España en el art. 24.2 de nuestra Constitución.

$3^{\circ}$. Otra creación gaditana (en el art. 293), es el llamado «Libro de Presos» que busca evitar la figura del «desaparecido» y ahorrar el instituto británico del «Habeas Corpus».

$4^{\circ}$. El art. 297 prohibió los «calabozos subterráneos o malsanos». Expresión descriptiva de gran parte de los calabozos de la época.

$5^{\circ}$. Se incluye un original mandato constitucional (en el art. 298) para que el legislador determine la frecuencia «con que ha de hacerse la visita de cárceles», figura que ganó gran relieve cuando en I864 el Gobierno, bajo el influjo gaditano, nombró a Concepción Arenal «Visitadora General de Prisiones». Ella publicaría después en francés su libro «El visitador del preso», pues a los franceses les interesaba el modelo español.

$6^{\circ}$. El art. 299 constitucionalización un mandato al legislador penal para tipificar en el Código Criminal el delito de «detención arbitraria», figura imitada por el art. 99 de la Constitución noruega de I8I4, aún hoy vigente.

$7^{\circ}$. La original constitucionalización (en el art. 30I) de que al reo se le lean de inmediato e íntegramente todos los documentos de la causa, las declaraciones de los testigos y el nombre de estos. No que les lean sus derechos.

8. La prohibición absoluta (en el art. 303) del tormento y de los apremios. Prohibición que asumió dos años después miméticamente el art. 96 de la Constitución noruega de I8I4.

$9^{\circ}$. Ignorando el Derecho Navarro esgrimido a la contra en el debate, se estableció, en el art. 304, la prohibición también absoluta de la pena de confiscación de bienes que sirve también de modelo a la Constitución noruega, y en el siguiente del Texto de Cádiz se prohíbe que cualquier pena afecte a la familia del penado.

I0 ${ }^{\circ}$ El art. 306 constitucionalización la inviolabilidad del domicilio de todo español, salvo en los términos autorizados por la ley. Estamos aquí, como en los casos anteriormente enumerados, ante la primera piedra de esta garantía de raíz histórica: Cervantes había puesto en boca del Quijote unas palabras que hacen vibrar el aire en la Isla 
de León: «estás en tu casa, donde eres señor de ella como el Rey de sus alcabalas». Un Lord inglés mucho después, en I764 sostuvo en un debate: «El hombre más pobre desafía en su recinto a todas las fuerzas de la Corona, su chimenea puede estar fría, su tejado puede temblar, el viento soplar entre las puertas desencajadas, la tormenta puede entrar, pero el Rey de Inglaterra no puede penetrar».

La constitucionalización de este Derecho al ubicarse en el Título V implicaba que la Ley regularía los mandatos judiciales «ad hoc». Nada tiene que ver este mandato constitucional con el del artículo i2 6 de la Constitución otorgada de Bayona conforme al cual: «No se podrá entrar en las casas sino de día, y para un objeto especial determinado por una Ley o por una Orden que dimane de la autoridad pública». Lo que no pasaba de ser una pequeña consideración al Derecho de conciliar el sueño, que, por lo demás, nunca respetaron las tropas napoleónicas.

II ${ }^{\circ}$. El art. 247 de nuestra Constitución de I8ı2 dispuso: «Ningún español podrá ser juzgado ... sino por el tribunal competente determinado con anterioridad por la Ley», antecedente del art. 24.2 de la Constitución de 1978: «Todos tienen derecho al juez ordinario predeterminado por la ley».

No traeremos a colación más ejemplos. Lo más importante de estas aportaciones es concluir que el alto número de diputados reunidos en Cádiz, que eran buenos juristas prácticos, aún conociendo el escaso Derecho Constitucional comparado de la época, no deducen del mismo el Título V. Su enfoque no es dogmático, sino práctico. Pusieron en cuestión los vicios de la degradada Justicia absolutista y buscaron finas soluciones constitucionales casuísticas y a la medida para modificar la realidad histórica de unos tribunales que operaban sin garantías y sin prestigio social.

Por lo demás, este Titulo V en su voluntad garantista desciende a concreciones sin precedentes, reflejo de la importancia capital que aquellos liberales otorgaban a la administración de Justicia, que les había llevado, en el «Discurso Preliminar» a aseverar: «la observancia de las formalidades que arreglan el proceso es tan esencial, que en ellas ha de estar fundado el criterio de la verdad»; lo que desembocó en constitucionalizar generosamente materias que hoy no consideraríamos de rango constitucional. Muchas de aquellas disposiciones «al observar las cosas con serenidad desde la perspectiva actual se nos aparece como evidente (que) la Iglesia heredada del pasado padecía de análogo abigarramiento al de otras estructuras del Antiguo Régimen, que eran resultado de un orden histórico, pero que no respondían a un orden lógico, ni se acomodaban a las realidades presentes».

Llegada la sesión de i6 de noviembre de I8II, se sometió a deliberación del Pleno el texto propuesto por la Comisión de Constitución para el artículo 248, que, pese a los problemas a que acabamos de aludir, disponía: «Los eclesiásticos continuarán gozando del fuero de su estado en los términos que prescriben las leyes, o que en adelante prescribieren».

En el debate sobre la jurisdicción eclesiástica se perfilaron dos sectores de diputados: Uno inspirado en un liberalismo purista que propuso no aprobar este precepto, para así suprimir el derecho de los eclesiásticos a gozar de su propio fuero, o, al menos limitarlo «a sus justo límites»-léase: «al ejercicio de su ministerio»-. Este grupo, encabezado por Calatrava y el conde de Toreno, con el respaldo de García Herreros, invocó que el Fuero eclesiástico era desconocido en el Fuero Juzgo y unilateralmente concedido en la Ley de Partidas para la autoridad Tempoal, que igualmente podía revocarlo per se. El otro sector apoyó el texto que en la Comisión de Constitución había propiciado Argüelles y contó con intervenciones de tono moderado (tácitamente apoyadas en la expresa confesionalidad católica proclamada por el art. I2 de la propia Constitución y reflejado en los artículos 79, 86, II7, I96 y 366) por parte de Dou, Güereña, el obispo de Calahorra y Villanueva, 
aprobándose el precepto en sus propios términos, con lo que la lex superior de I8I2 se apartaba en este punto, como en tantos, de la Constitución francesa de I79I.

Antes de plantearse el debate, al que nos referiremos, sobre el reconocimiento de la jurisdicción militar, ya en marzo de I8II, la Comisión de Guerra había examinado un proyecto presentado por el Consejo de Regencia para el establecimiento de un «tribunal de honor en los Ejércitos», cuya principal misión era perseguir los casos de cobardía que se atribuían especialmente a la forma acelerada e irregular en que se reclutaron tropas para combatir contra el entonces mejor Ejército del mundo. Entre las intervenciones en el debate citaremos la de Esteban que terminó así: «Por lo que a mí toca tengo por inútil este tribunal de honor, y me daría por muy satisfecho con la rigurosa observancia de la ordenanza militar. Concluyo diciendo que el verdadero honor consiste en matar franceses; y en caso que existiese este tribunal, solo debía dirigirse a la investigación de los que se distinguiesen en este importante servicio, declarando el honor al que mate ciento, más honor al que mate doscientos y así sucesivamente». Argüelles se empleó a fondo en pro de la instauración de tales tribunales de honor en una intervención brillante en la que acabó haciendo la concesión de que se instituyese con carácter provisional, a modo de ensayo, hasta extraer una experiencia, que de no ser positiva conduciría a su supresión. Por votación se aprobó su instauración y se encomendó la redacción de su Reglamento.

Algunos meses después, la propuesta de un fuero especial para los militares generó discusión más tensa que lo habitual. La Comisión había elevado como propuesta de artículo 249 la siguiente redacción: «Los militares gozarán también de fuero particular en los delitos que se oponen a la disciplina, según lo determinare la ordenanza». Abrió el fuego contra tal texto Laguna, con léxico que destilaba acusaciones de ingratitud de las Cortes hacia los soldados que «nos defienden» y «pueden devolvernos la Nación», por entonces parcialmente ocupada por las tropas francesas.

Tras el debate, el texto del precepto fue rechazado y devuelto a la Comisión. Más adelante se aprobó sin el límite de los delitos referidos a la disciplina. Por supuesto el que aquella España dependiese de las armas tuvo mucho que ver con la actitud de las Cortes.

Como síntesis del tratamiento constitucional a los dos fueros extraordinarios cabe decir que constituye buena muestra del realismo que los liberales reunidos en Cádiz asumieron en búsqueda de una transacción con la España profunda.

Pasemos página. Durante la Ilustración, la Inquisición había decaído notablemente, aunque mantuvo actividad respecto de la expansión del jansenismo y del enciclopedismo francés. Y el prestigio del Santo Oficio se encontraba en cotas bajas. El Conde de Aranda había planteado, en su día, la supresión de la Inquisición aunque sin llegar a persuadir de ello a Carlos III. Durante los reinados de Carlos III y Carlos IV «sólo» diez personas fueron condenadas a muerte, a la par que, según se dice, se abandonó el empleo de la tortura. Se trataba de un Tribunal que actuaba sensiblemente más con fines políticos que religiosos, muy centrado en la censura de libros, especialmente de los que difundían las ideas revolucionarias, por socavar la obediencia debida al Rey de España. La Inquisición había sido una de las pruebas más palpables del triunfo de las tesis regalistas, desde, al menos, el siglo XVII, y particularmente en la España Ilustrada.

Esa Inquisición ya mortecina fue suprimida en España por Napoleón (no por José Bonaparte) en I808 y constituyó objeto en las Cortes de Cádiz de un tratamiento singular. La Constitución de I8ı2 guardó silencio sobre ella. Pero el consenso sobre eludir su constitucionalización fue compatible con algún debate puntual con alusiones al Santo Oficio.

En efecto, el i6 de mayo de i8iı los miembros del Consejo de la Suprema notificaron a la Regencia que se habían constituido y dos días después el Secretario del 
Despacho de Gracia y Justicia comunicó, a su vez, una Orden de la Regencia por la que se hacía saber a los tres inquisidores de la Suprema «lo extraño que le había sido su reunión, estando pendiente la resolución de S.M. sobre este asunto y mandándoles se abstuviesen de formar Consejo y ejercer sus funciones». La Inquisición no había sido derogada, pero su funcionamiento estaba en suspenso.

Se juró por los diputados la Constitución de ı8ı2. Habiendo abolido la tortura pero sin un pronunciamiento claro sobre si el Santo Oficio iba a mantenerse o suprimirse una vez entrase en vigor la Constitución. He comprobado que es errónea la cita de Vélez a un Decreto -según él- del i2 de marzo, una semana antes de que se jurase la Constitución, que entiende prohibía los Consejos del Santo Oficio. Tal Decreto es posterior, del I7 de abril, y en su art. I no prohíbe tales «consejos» sino otros. Creo que Vélez aquí no incurre en un mero error material sino que, como hizo tantas veces, trastoca los hechos con el fin de poder sostener que los liberales habían abolido el Santo Oficio en el último minuto del proceso constituyente por un Decreto que habría obviado el debate en las Cortes. Las actas y la literalidad y fecha del Decreto acreditan que sucedió todo lo contrario.

Otra faceta interesante de la Constitución gaditana es que asentado que jueces y magistrados son independientes en el desempeño de la potestad de juzgar, pareció obligado, conforme a los designios de la máxima de la más clásica escuela del Derecho público: «Donde está el poder, está la responsabilidad», que el art. 254 ordenase: «Toda falta de observancia de las leyes que arreglan el proceso en lo civil y en lo criminal, hace responsables personalmente a los jueces que la cometieren». Pero a tal lógica se sumaba otra de no menor relieve: la denominada aristocracia togada, incluido su más alto nivel, era renuente a ciertas reformas constitucionales en ciernes. No parece casualidad que a fines de I8II, cuando se discute este Título V de la Constitución arrecie la difusión de panfletos y folletos críticos sobre ciertos aspectos del mismo. Los absolutistas no aceptaban que una Justicia independiente para los españoles sustituyese a una Justicia del Rey para sus súbditos. Pero la Constitución del I2 garantizó a los jueces la máxima independencia y, al tiempo, les hizo responsables de sus resoluciones antijurídicas. Se constitucionalizó la posibilidad de perseguir, mediante acción popular, los delitos de soborno, cohecho y prevaricación.

En Cádiz, pese a la desconfianza de Montesquieu hacia los magistrados profesionales y su defensa de la figura de los temporales, se aceptaron ambos con independencia especialmente garantizada, y hubo, al tiempo, escasa admiración hacia la institución del jurado.

La diferencia entre el modelo anglosajón y el francés en materia de jurados era bien conocida y correctamente valorada por los Diputados reunidos en Cádiz. Mientras el modelo de jurado anglosajón supone un derecho fundamental del justiciable y una institución representativa, en el contra modelo francés más que un derecho es solo una garantía procesal, huérfana de un carácter representativo que no se reconoce a ningún órgano de la Justicia.

El artículo 307 de la Constitución gaditana es un precepto de caucho que eludía constitucionalizar el jurado, y que disponía: «Si con el tiempo creyeran las Cortes que haya distinción entre los jueces de hecho y de derecho, la establecerán en la forma que juzguen conducente». Mucho después, el artículo i25 de nuestra Constitución vigente -atento a las enseñanzas del I2 en materia de Justicia- supuso una análoga «larga cambiada».

Era lógico: el jurado de cuna anglosajona, había surgido al amparo del punto I4 de la Carta Magna (I2I2) y se desarrolló en Inglaterra bajo el reinado de Enrique III en el siglo XIII, sin ningún eco en nuestra tradición procesal. 
Del pormenorizado tratamiento que efectúa la Constitución del I2 sobre «la nueva planta de juzgados y tribunales» hay que destacar la instauración del denominado «Supremo Tribunal de Justicia», que es heredero del de la Constitución Norteamericana de I787, y no del «Tribunal de Casación» ni de la «Alta Corte Nacional», instaurados por la Constitución francesa de I79I.

Sobre su nombre y funciones numerosos diputados mantuvieron un debate de altura en que se analizan las experiencias extraídas de los más altos tribunales de Aragón y Castilla. A este supremo tribunal se atribuyen finalmente once funciones, aunque no el conocer del recurso de casación, pero sí del de nulidad de actuaciones -salvo en Ultramar donde el mismo estaba residenciado en las Audiencias- y una singular formulación de lo que hoy llamaríamos «unificación de doctrina», consistente en «oír las dudas de los demás tribunales sobre la inteligencia de alguna ley, y consultar sobre ellas al Rey con los fundamentos que hubiere, para que promueva la conveniente declaración en las Cortes».

Desde que los magistrados del Tribunal Supremos tomaron posesión hasta que se reguló este máximo Tribunal -Reglamento de marzo de I8I4- transcurrió un tiempo en que las funciones que desempeñó el Alto Tribunal fueron las que había ejercido el Consejo de Castilla, de manera que del primer Supremo Tribunal puede decirse que operó a su aire con cierta inercia histórica.

Termino: Fernando VII firmó en Valencia su Decreto de 4 de mayo de I8I4, declarando «nula y de ningún valor ni efecto la Constitución de las llamadas Cortes generales y extraordinarias de la Nación». En el que destacó el cuidado puesto en procurar no interrumpir la administración de la Justicia, que pese a las dificultades de la época, se gestionaba ya, por lo general, conforme a lo dispuesto en la Constitución de I8ı2 y con merecido prestigio.

Así en el único párrafo de este Decreto se dispuso: «Es mi voluntad que continúen las Justicias ordinarias de los pueblos que se hallan establecidas, los jueces de letras adonde los hubiere, y las Audiencias, Intendentes y demás Tribunales de Justicia en la administración de ella». Era un pequeño reconocimiento tácito de la superioridad del régimen judicial liberal sobre el absoluto efectuado por un Monarca que no reconocería, al menos hasta el trienio liberal, ninguna otra virtud a la Constitución gaditana. Termino formulando una afirmación sin titubeos: Todos los presentes podemos estar orgullosos de nuestros tatarabuelos protagonistas del proceso constituyente gaditano hace doscientos años eran unos españoles cultos y a la altura de su tiempo, que iluminaron el camino por el que habría de avanzar la organización de la justicia en la Europa contemporánea. 